\title{
Transient Stability Enhancement of Multimachine Power System Using Robust and Novel Controller Based CSC-STATCOM
}

\author{
Sandeep Gupta ${ }^{1}$ and Ramesh Kumar Tripathi ${ }^{2}$ \\ ${ }^{1}$ Department of Electrical Engineering, RIET, Jaipur 302026, India \\ ${ }^{2}$ Department of Electrical Engineering, MNNIT, Allahabad 211004, India \\ Correspondence should be addressed to Sandeep Gupta; jecsandeep@gmail.com
}

Received 3 August 2014; Revised 22 December 2014; Accepted 23 December 2014

Academic Editor: Francesco Profumo

Copyright (C) 2015 S. Gupta and R. K. Tripathi. This is an open access article distributed under the Creative Commons Attribution License, which permits unrestricted use, distribution, and reproduction in any medium, provided the original work is properly cited.

\begin{abstract}
A current source converter (CSC) based static synchronous compensator (STATCOM) is a shunt flexible AC transmission system (FACTS) device, which has a vital role as a stability support for small and large transient instability in an interconnected power network. This paper investigates the impact of a novel and robust pole-shifting controller for CSC-STATCOM to improve the transient stability of the multimachine power system. The proposed algorithm utilizes CSC based STATCOM to supply reactive power to the test system to maintain the transient stability in the event of severe contingency. Firstly, modeling and pole-shifting controller design for CSC based STATCOM are stated. After that, we show the impact of the proposed method in the multimachine power system with different disturbances. Here, applicability of the proposed scheme is demonstrated through simulation in MATLAB and the simulation results show an improvement in the transient stability of multimachine power system with CSCSTATCOM. Also clearly shown, the robustness and effectiveness of CSC-STATCOM are better rather than other shunt FACTS devices (SVC and VSC-STATCOM) by comparing the results in this paper.
\end{abstract}

\section{Introduction}

The continuous developments of electrical loads due to the modification of the society structure result in today's transmission structure to be faced close to their stability restrictions. So the renovation of urban and rural power network is more and more necessary. Due to governmental, financial, and green climate reasons, it is not always possible to construct new transmission lines to relieve the power system stability problem at the existing overloaded transmission lines. As a result, the utility industry is facing the challenge of efficient utilization of the existing AC transmission lines in power system networks. So transient stability, voltage regulation, damping oscillations, and so forth are the most important operating issues that electrical engineers are facing during power transfer at high levels.

In above power quality problems, transient stability is one of the most important key factors during power transfer at high levels. According to the literature, transient stability of a power system is its ability to maintain synchronous operation of the machines when subjected to a large disturbance [1]. While the generator excitation system with PSS (power system stabilizer) can maintain excitation control and stability it is not adequate to sustain the stability of power system for large faults or overloading occurs near to generator terminals [2].

So many researchers worked on this problem in finding the solution for a long time. These solutions are such as using wide-area measurement signals [3], phasor measurement unit [4], and flexible $\mathrm{AC}$ transmission system. In these solutions, one of the powerful methods for enhancing the transient stability is to use flexible AC transmission system (FACTS) devices [5-8]. Even though the prime objective of shunt FACTS devices (SVC, STATCOM) is to maintain bus voltage by absorbing (or injecting) reactive power, they are also competent of improving the system stability by diminishing (or increasing) the capability of power transfer when the machine angle decreases (increases), which is accomplished 
by operating the shunt FACTS devices in inductive (capacitive) mode.

In many research papers [2, 9-11], the different types of these devices with different control techniques are used for improving transient stability. In between these FACTS devices, the STATCOM is valuable for enhancement power system dynamic stability and frequency stabilization due to the more rapid output response, lower harmonics, superior control stability and small size, and so forth $[7,12]$. By their inverter configuration, basic type of STATCOM topology can be realized by either a current-source converter (CSC) or a voltage-source converter (VSC) [13-17]. But recent research confirms several merits of CSC based STATCOM over VSC based STATCOM [18, 19]. These advantages are high converter reliability, quick starting, and inherent shortcircuit protection, and the output current of the converter is directly controlled and in low switching frequency this reduces the filtering requirements compared with the case of a VSC. Therefore CSC based STATCOM is very useful in power systems rather than VSC based STATCOM in many cases.

Presently the most used techniques for controller design of FACTS devices are the Proportional Integration (PI), PID controller [20], pole-shifting controller, and linear quadratic regulator (LQR) [21]. But LQR and pole-shifting algorithms give quicker response in comparison to PI and PID algorithm [22]. LQR controller gain $(K)$ can be calculated by solving the Riccati equation and $K$ is also dependent on the two cost functions $(Q, R)$. So Riccati equation solvers have some limitations, which relate to the input arguments. But pole shifting method does not face this type of any problem. So pole shifting method gives a better and robust performance in comparison to other methods.

The main contribution of this paper is the application of proposed pole-shifting controller based CSC-STATCOM for improvement of power system stability in terms of transient stability by injecting (or absorbing) reactive power. In this paper, the proposed scheme is used in the multimachine power transmission system with dynamic loads under a grievous disturbance condition (three-phase fault or heavy loading) to enhancement of power system transient stability studies and to observe the impact of the CSC based STAT$\mathrm{COM}$ on electromechanical oscillations and transmission capacity. Furthermore, the obtained outcomes from the proposed algorithm based CSC-STATCOM are compared to the obtained outcomes from the other shunt FACTS devices (SVC and VSC-STATCOM) which are used in previous works $[23,24]$.

The rest of the paper is prepared as follows. Section 2 discusses the circuit modeling and proposed pole-shifting controller designing for CSC based STATCOM. A two-area power system is described with a CSC-STATCOM device in Section 3. Simulation results of the test system with and without CSC based STATCOM for severe contingency are shown in Section 4, to improve the transient stability of the multimachine power system. Comparison among different shunt FACTS devices (SVC, VSC-STATCOM, and CSCSTATCOM) is also described in Section 4. Finally, Section 5 concludes this paper.

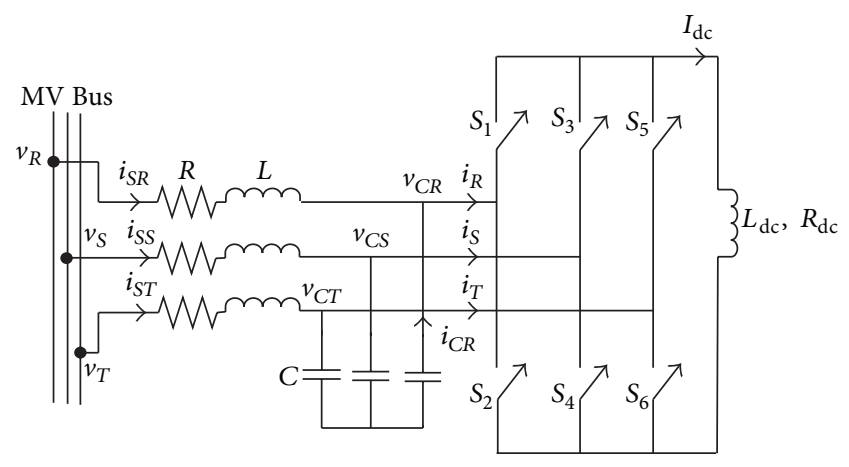

FIGURE 1: The representation of CSC based STATCOM. $i_{S R}, i_{S S}, i_{S T}$ : line current; $v_{C R}, v_{C S}, v_{C T}$ : voltages across the filter capacitors; $v_{R}, v_{S}$, $v_{T}$ : line voltages; $I_{\mathrm{dc}}$ : dc-side current; $R_{\mathrm{dc}}$ : converter switching and conduction losses; $L_{\mathrm{dc}}$ : smoothing inductor; $C$ : filter capacitance; $L$ : inductance of the line reactor; $R$ : resistance of the line reactor.

\section{Mathematical Modeling of Pole-Shifting Controller Based CSC-STATCOM}

2.1. CSC Based STATCOM Model. In this section, to verify the response of the STATCOM on dynamic performance, the mathematical modeling and control strategy of a CSC based STATCOM are needed to be presented. So in the designing of controller for CSC based STATCOM, the state space equations from the CSC-STATCOM circuit must be introduced. To minimize the complexity of mathematical calculation, the theory of $d q$ transformation of currents has been applied in this circuit, which makes the $d$ and $q$ components independent parameters. Figure 1 shows the circuit diagram of a typical CSC based STATCOM.

The basic mathematical equations of the CSC based STATCOM have been derived in the literature [19]. Therefore, only brief details of the primary equations for CSCSTATCOM are given here for the readers' convenience. Based on the equivalent circuit of CSC-STATCOM as shown in Figure 1, the differential equations for the system can be achieved, which are derived in the abc frame and then transformed into the synchronous $d q$ frame using $d q$ transformation method [25]:

$$
\begin{gathered}
\frac{d}{d t} I_{\mathrm{dc}}=-\frac{R_{\mathrm{dc}}}{L_{\mathrm{dc}}} I_{\mathrm{dc}}-\frac{3}{2 L_{\mathrm{dc}}} M_{d} V_{d}-\frac{3}{2 L_{\mathrm{dc}}} M_{q} V_{q}, \\
\frac{d}{d t} I_{d}=-\frac{R}{L} I_{d}+\omega I_{q}-\frac{1}{L} \frac{E_{d}}{n}+\frac{1}{L} V_{d}, \\
\frac{d}{d t} I_{q}=-\omega I_{d}-\frac{R}{L} I_{q}+\frac{1}{L} V_{q}, \\
\frac{d}{d t} V_{d}=-\frac{1}{C} I_{d}+\omega V_{q}+\frac{1}{C} M_{d} I_{\mathrm{dc}}, \\
\frac{d}{d t} V_{q}=-\frac{1}{C} I_{q}-\omega V_{d}+\frac{1}{C} M_{q} I_{\mathrm{dc}} .
\end{gathered}
$$

In above differential equations $M_{d}$ and $M_{q}$ are the two input variables. Two output variables are $I_{\mathrm{dc}}$ and $I_{q}$. Here, $\omega$ is the rotation frequency of the system and this is equal to the 
nominal frequency of the system voltage. $I_{d}$ and $I_{q}$ are the $d$ axis and $q$-axis components of the line current. $M_{d}$ and $M_{q}$ are $d$-axis and $q$-axis components of the system modulating signal, respectively. $E_{d}$ and $E_{q}$ are direct and quadrature axis of system voltage. Here $E_{q}$ is taken as a zero. $V_{d}$ and $V_{q}$ are the $d$-axis and $q$-axis components of the voltage across filter capacitor, respectively.

Equation (1) shows that controller for CSC based STAT$\mathrm{COM}$ has nonlinearity characteristic. So this nonlinear property can be removed by accurately modeling of CSC based STATCOM. From (1) to (5), it can be seen that nonlinear property in the CSC-STATCOM model is due to the part of $I_{\mathrm{dc}}$. This nonlinear property is removed with the help of active power balance equation. Here, it has been assumed that the power loss in the switches and resistance $R_{\mathrm{dc}}$ is ignored and the turns ratio of the shunt transformer is $n: 1$. Here it is considered that generated power from the AC-source side $\left(P_{\mathrm{ac}}\right)$ is equal to absorbed power by DC-source side $\left(P_{\mathrm{dc}}\right)$ and power loss at this time is negligible. So this can be written in equation form as

$$
P_{\mathrm{ac}}=P_{\mathrm{dc}} \Longrightarrow-\frac{3 E_{d}}{2 n} I_{d}=L_{\mathrm{dc}} I_{\mathrm{dc}} \frac{d}{d t} I_{\mathrm{dc}}+R_{\mathrm{dc}} I_{\mathrm{dc}}^{2} .
$$

After using power balance equation and mathematical calculation, nonlinear characteristic is removed from (1). Finally the equation is obtained below:

$$
\frac{d}{d t}\left(I_{\mathrm{dc}}^{2}\right)=-\frac{2 R_{\mathrm{dc}}}{L_{\mathrm{dc}}}\left(I_{\mathrm{dc}}^{2}\right)-\frac{3 E_{d}}{L_{\mathrm{dc}} n} I_{d} .
$$

In (7) state variable $\left(I_{\mathrm{dc}}\right)$ is replaced by the state variable $\left(I_{\mathrm{dc}}^{2}\right)$, to make the dynamic equation linear. Finally the resulting better dynamic and robust model of the STATCOM in matrix form can be derived as

$$
\begin{aligned}
\frac{d}{d t}\left[\begin{array}{c}
\left(i_{\mathrm{dc}}\right)^{2} \\
i_{d} \\
i_{q} \\
v_{c d} \\
v_{c q}
\end{array}\right]= & {\left[\begin{array}{ccccc}
-\frac{2 R_{\mathrm{dc}}}{L_{\mathrm{dc}}} & \frac{3 E_{d}}{L_{\mathrm{dc}} n} & 0 & 0 & 0 \\
0 & -\frac{R}{L} & \omega_{o} & \frac{1}{L} & 0 \\
0 & -\omega_{o} & -\frac{R}{L} & 0 & \frac{1}{L} \\
0 & -\frac{1}{C} & 0 & 0 & \omega_{o} \\
0 & 0 & -\frac{1}{C} & -\omega_{o} & 0
\end{array}\right] *\left[\begin{array}{c}
\left(i_{\mathrm{dc}}\right)^{2} \\
i_{d} \\
i_{q} \\
v_{c d} \\
v_{c q}
\end{array}\right] } \\
& +\left[\begin{array}{cc}
0 & 0 \\
0 & 0 \\
0 & 0 \\
\frac{1}{C} & 0 \\
0 & \frac{1}{C}
\end{array}\right] *\left[\begin{array}{c}
I_{i d} \\
I_{i q}
\end{array}\right]+\left[\begin{array}{c}
0 \\
-\frac{1}{L} \\
0 \\
0 \\
0
\end{array}\right] * E_{d} .
\end{aligned}
$$

Above modeling of CSC based STATCOM is written in the form of modern control methods, that is, state-space representation. For state-space modeling of the system, next section has been considered.
2.2. Pole-Shifting Controller Design. The pole-shifting technique is one of the basic control methods which are employed in feedback control system theory. Theoretically pole-shifting technique is to set the preferred pole position and to move the pole position of the system to that preferred pole position, to get the desired system outcomes [26]. Here poles of system are shifted because the position of the poles related directly to the eigenvalues of the system, which control the dynamic characteristics of the system outcomes. But for this method, the system must be controllable. In the dynamic modeling of systems, state-space equations involve three types of variables: state variables $(x)$ and input $(u)$ and output $(y)$ variables with disturbance (e). So comparing (8) with the standard state-space representation, that is,

$$
\begin{gathered}
\dot{x}=A x+B u+F e, \\
y=C x .
\end{gathered}
$$

We get the system matrices as

$$
\begin{gathered}
x=\left[\begin{array}{lllll}
I_{\mathrm{dc}}^{2} & i_{d} & i_{q} & V_{d} & V_{q}
\end{array}\right]^{T} ; \quad u=\left[\begin{array}{ll}
I_{i d} & I_{i q}
\end{array}\right]^{T} ; \\
e=E_{d} ; \quad y=\left[\begin{array}{llll}
I_{\mathrm{dc}}^{2} & I_{q}
\end{array}\right]^{T}, \\
A=\left[\begin{array}{crccc}
-\frac{2 R_{\mathrm{dc}}}{L_{\mathrm{dc}}} & -\frac{3 E_{d}}{L_{\mathrm{dc}}} & 0 & 0 & 0 \\
0 & -\frac{R}{L} & \omega & \frac{1}{L} & 0 \\
0 & -\omega & -\frac{R}{L} & 0 & \frac{1}{L} \\
0 & -\frac{1}{c} & 0 & 0 & \omega \\
0 & 0 & -\frac{1}{c} & -\omega & 0
\end{array}\right] ; \quad B=\left[\begin{array}{cc}
0 & 0 \\
0 & 0 \\
0 & 0 \\
\frac{1}{c} & 0 \\
0 & \frac{1}{c}
\end{array}\right] ; \\
C=\left[\begin{array}{cc}
1 & 0 \\
0 & 0 \\
0 & 1 \\
0 & 0 \\
0 & 0
\end{array}\right]^{T} \quad ; \quad F=\left[\begin{array}{c}
0 \\
-\frac{1}{L} \\
0 \\
0 \\
0
\end{array}\right] .
\end{gathered}
$$

In the above equations (9) five system states, two control inputs, and two control outputs are presented, where $x$ is the state vector, $u$ is the input vector, $A$ is the basis matrix, $B$ is the input matrix, and $e$ is disturbance input.

If the controller is set as

$$
u=-K * x+J * y_{\text {ref }}+N * e,
$$

then the state equation of closed loop can be written as

$$
\dot{x}=(A-B * K) * x+J * y_{\text {ref }}+B * N * e+F * e .
$$

Here, for steady state condition:

$$
\dot{x}=0 \text {. }
$$

Then,

$y=C *(A-B * K)^{-1} *\left[B * J * y_{\mathrm{ref}}+B * N * e+F * e\right]$, 


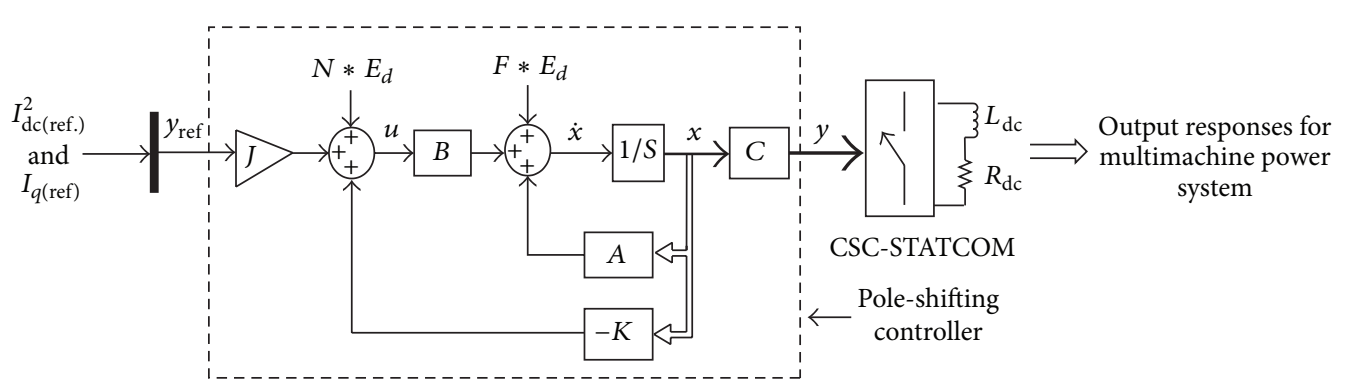

FIGURE 2: Control structure of pole-shifting controller based CSC-STATCOM.

where $J=\left(C *\left(-(A-B * K)^{-1}\right) * B\right)^{-1}$ and $N=((C *(-A+B *$ $\left.\left.K)^{-1} * B\right)\right)^{-1} *\left(C *(-A+B * K)^{-1} * F\right)$; these constant values are found out from a mathematical calculation for tracking the reference output value $\left(y_{\text {ref }}\right)$ by the system output value $(y)$. Here $K$ is the state-feedback gain matrix. The gain matrix $K$ is designed in such a way that (15) is satisfied with the desired poles:

$$
|s I-(A-B K)|=\left(s-P_{1}\right)\left(s-P_{2}\right) \cdots\left(s-P_{n}\right),
$$

where $P_{1}, P_{2}, \ldots, P_{n}$ are the desired pole locations. Equation (15) is the desired characteristic polynomial equation. The values of $P_{1}, P_{2}, \ldots, P_{n}$ are selected such that the system becomes stable and all closed-loop eigenvalues are located in the left half of the complex-plane. The final configuration of the proposed pole-shifting controller based CSC-STATCOM is shown in Figure 2.

All the required parameters for the structure of poleshifting controller based CSC-STATCOM are given in the appendix.

\section{Two-Area Power System with CSC-STATCOM Facts Device}

In this section, consider a two-area power system with a CSCSTATCOM at bus $b$ is connected through a long transmission system, where CSC-STATCOM is used as a shunt current source device. Figure 3 shows this type of representation. The dynamic model of the machine, with a CSC-STATCOM, can be written in the differential algebraic equation form as follows:

$$
\begin{gathered}
\dot{\delta}=\omega, \\
\dot{\omega}=\frac{1}{M}\left[P_{m}-P_{e o}-P_{e}^{\mathrm{csc}}\right] .
\end{gathered}
$$

Here $\omega$ is the rotor speed, $\delta$ is the rotor angle, $P_{m}$ is the mechanical input power of generator, the output electrical power without CSC-STATCOM is represented by $P_{e o}$, and $M$ is the moment of inertia of the rotor. Equation (17) is also called swing equation. The additional factor of the output electrical power of generator from a CSC-STATCOM is $P_{e}^{\text {csc }}$ in the swing equation.

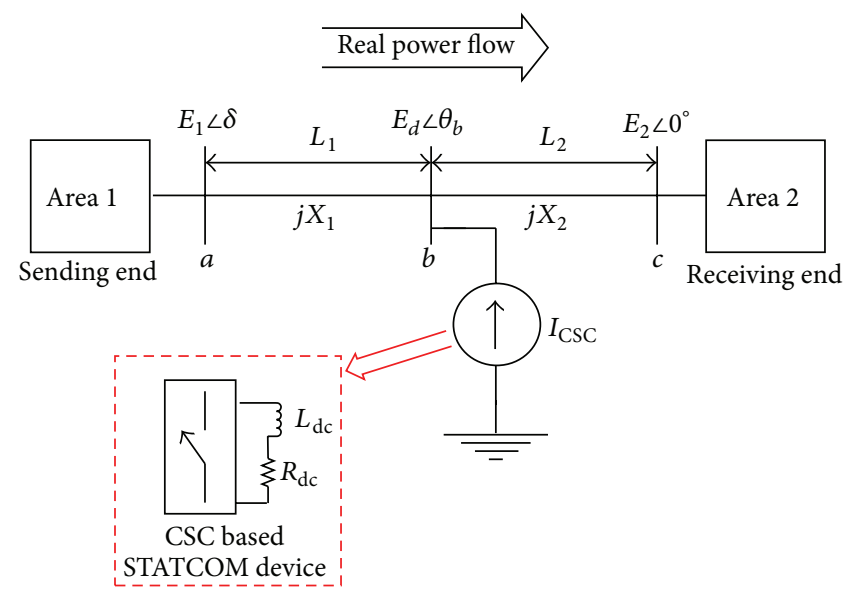

FIGURE 3: A single line diagram of two-area power system with CSCSTATCOM.

Here for calculation of $P_{e}^{\mathrm{csc}}$, we assume the CSCSTATCOM works in capacitive mode. Then the injected current from CSC-STATCOM to test system can be written as

$$
I_{\mathrm{csc}}=I_{\mathrm{csc}} \angle\left(\theta_{b o}-90^{\circ}\right) \text {, }
$$

where $\theta_{b o}$ is the voltage angle at bus $b$ in absentia of CSCSTATCOM. In Figure 3 , the magnitude $\left(E_{d}\right)$ and angle $\left(\theta_{b}\right)$ of voltage at bus $b$ can be computed as

$$
\begin{gathered}
\theta_{b}=\tan ^{-1}\left[\frac{X_{2} E_{1} \sin \delta}{X_{2} E_{1} \cos \delta+X_{1} E_{2}}\right], \\
E_{d}=\left(\frac{X_{2} E_{1} \cos \left(\delta-\theta_{b o}\right)+X_{1} E_{2} \cos \theta_{b o}}{X_{1}+X_{2}}\right) \\
+\left(\frac{X_{1} X_{2}}{X_{1}+X_{2}} I_{\mathrm{csc}}\right) .
\end{gathered}
$$

From (20), it can be said that the voltage magnitude of bus $b\left(E_{d}\right)$ depends on the STATCOM current $\left(I_{\mathrm{csc}}\right)$. In (17), the electrical output power $P_{e}^{\mathrm{csc}}$ of machine due to a CSCSTATCOM can be expressed as

$$
P_{e}^{\mathrm{csc}}=\frac{E_{1} E_{d}}{X_{1}} \sin \left(\delta-\theta_{b}\right) .
$$




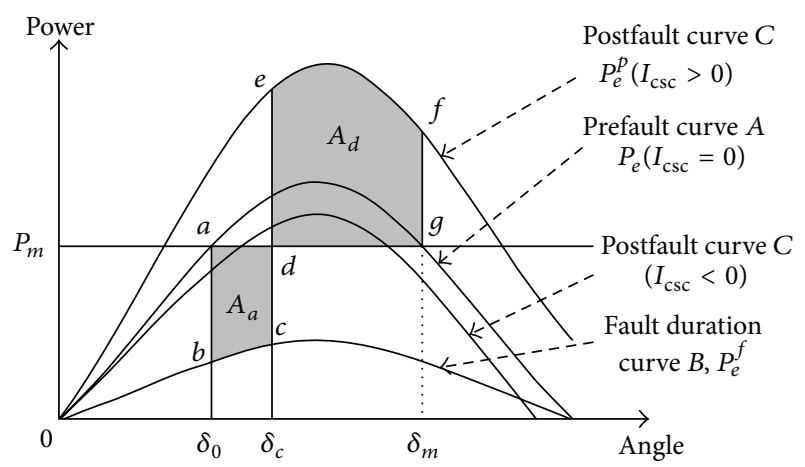

FIGURE 4: Power-angle characteristic of the test system with a CSCSTATCOM.

Finally, using (20) and (21) the total electrical output $\left(P_{e}\right)$ of machine with CSC-STATCOM can be written as

$$
\begin{aligned}
P_{e} & =P_{e o}+P_{e}^{\mathrm{csc}} \\
& \Longrightarrow P_{e}=P_{e o}+\frac{X_{1} X_{2} E_{1}}{\left(X_{1}+X_{2}\right) X_{1}} I_{\mathrm{csc}} \sin \left(\delta-\theta_{b}\right) .
\end{aligned}
$$

All above equations are represented for the capacitive mode of CSC-STATCOM. So if the inductive mode of operation is needed in the system then $I_{\text {csc }}$ is replaced by $-I_{\text {csc }}$ in (18), (20), and (22). With the help of (17), the power-angle curve of the test system can be drawn for stability analysis as shown in Figure 4.

The power-angle $(P-\delta)$ curve of the test system without a CSC-STATCOM is represented by curve $A$ (also called prefault condition) in Figure 4. Here the mechanical input is $P_{m}$, electrical output is $P_{e}$, and initial angle is $\delta_{0}$. When a fault occurs, $P_{e}$ suddenly decreases and the operation shifts from point $a$ to point $b$ at curve $B$ and thus the machine starts accelerating from point $b$ to point $c$, where accelerating power $\left[P_{a}=\left(P_{m}-P_{e}\right)\right]>0$. At fault clearing, $P_{e}$ suddenly increases and the area $a-b-c-d-a$ represents the accelerating area $A_{a}$ as defined in (23). If the CSC-STATCOM operates in a capacitive mode (at fault clearing), $P_{e}$ increases to point $e$ at curve $C$ (also called postfault condition). At this time $P_{a}$ is negative. Thus the machine starts decelerating but its angle continues to increase from point $e$ to the point $f$ until it reaches a maximum allowable value $\delta_{m}$ at point $f$, for system stability. The area $e-f-g-d-e$ represents the decelerating area $A_{d}$ as defined in (23). From previous literature [1], equal area criterion for stability of the system can be written as

$$
\int_{\delta_{0}}^{\delta_{c}}\left(P_{m}-P_{e}^{f}\right) d \delta=\int_{\delta_{c}}^{\delta_{m}}\left(P_{e}^{p}-P_{m}\right) d \delta \Longrightarrow A_{a}=A_{d}
$$

This equation is generated from Figure 4 , where $\delta_{c}$ is critical clearing angle. $P_{e}^{P}$ is an electrical output for postfault condition. $P_{e}^{f}$ is an electrical output during fault condition. From Figure 4 we clearly see, for capacitive mode operation $\left(I_{\text {csc }}>0\right)$ of CSC-STATCOM device, the $P$ - $\delta$ curve is not only uplifted but also displaced toward right and that endues more decelerating area and hence higher stability limit. After that Section 4 is considered, to verify the impact of the proposed controller based CSC-STATCOM modeling in the analysis of the multimachine power system stability in terms of transient stability studies.

\section{Simulation Results}

4.1. Multimachine Power System under Study. In this section, two-area four-machine power system is considered for the test system study. For this type of test system, a $500 \mathrm{kV}$ transmission system with four hydraulic power plants (G1, G2, G3, and G4) connected through 500-km long transmission line is taken as shown in Figure 5. Here combination of machine G1 and machine G2 represents the area 1 and combination of machine G3 and machine G4 represents the area 2. A rating of first (G1) and second (G2) power generation plant is $13.8 \mathrm{kv} / 1000 \mathrm{MVA}$. The electrical outputs of the third (G3) and fourth (G4) power plant are 3000 MVA. One $6000 \mathrm{MW}$ large resistive load is connected at the bus B3 and another $1000 \mathrm{MW}$ resistive load is connected at the bus $\mathrm{B} 1$ as shown in Figure 5. In this figure, $828 \mathrm{MW}$ power is flowing through bus B2, $944 \mathrm{MW}$ and $877 \mathrm{MW}$ power are flowing through buses B4 and B5, respectively, and $2487 \mathrm{MW}$ and $2643 \mathrm{MW}$ power are flowing through buses B6 and B7, respectively. These values are based on power flow calculation. To improve the transient stability of the test-system after disturbances (faults or heavy loading), a pole-shifting controller based CSC-STATCOM is connected at the mid-point of transmission line (at bus B2). In order to previous work [27], shunt FACTS devices give maximum efficiency when connected at the mid-point of transmission line. Here each hydraulic generating unit is assembled with a turbine-governor set, excitation system, and synchronous generator. But the hydraulic generating unit is not explained in this paper. This is explained in [1]. All the data required for this test system model are given in the appendix.

Now a severe contingency will be applied to the test system and to observe the impact of the pole-shifting controller based CSC-STATCOM for maintaining the system stability through MATLAB/SIMULINK.

4.2. Case I-Short-Circuit Fault. In this case, it is considered that a three-phase fault is occurring at near bus $\mathrm{B} 1$ at $t=$ $0.1 \mathrm{~s}$ and is cleared at $0.277 \mathrm{~s}$. The impact of system with and without CSC based STATCOM to this disturbance is shown in Figures 6, 7, 8, 9, and 10. Here simulation is carried out for $9 \mathrm{~s}$ to observe the nature of transients. It is clear that the system without CSC-STATCOM is unstable upon the clearance of the fault from Figures 6 to 8. But this system with pole-shifting controller based CSC-STATCOM is restored and stable upon the clearance of the fault and settled down after about 3 to $4 \mathrm{~s}$ in Figures 7 to 10. Synchronism in between four machine system is also maintained in these figures. In Figure $7, \delta_{1}, \delta_{2}, \delta_{3}$, and $\delta_{4}$ are the rotor angles of machines G1, G2, G3, and G4, respectively. Figure 7 represents the variation of rotor angles differences of the multimachine system. In Figure 8, speed of machines G1, G2, G3, and G4 


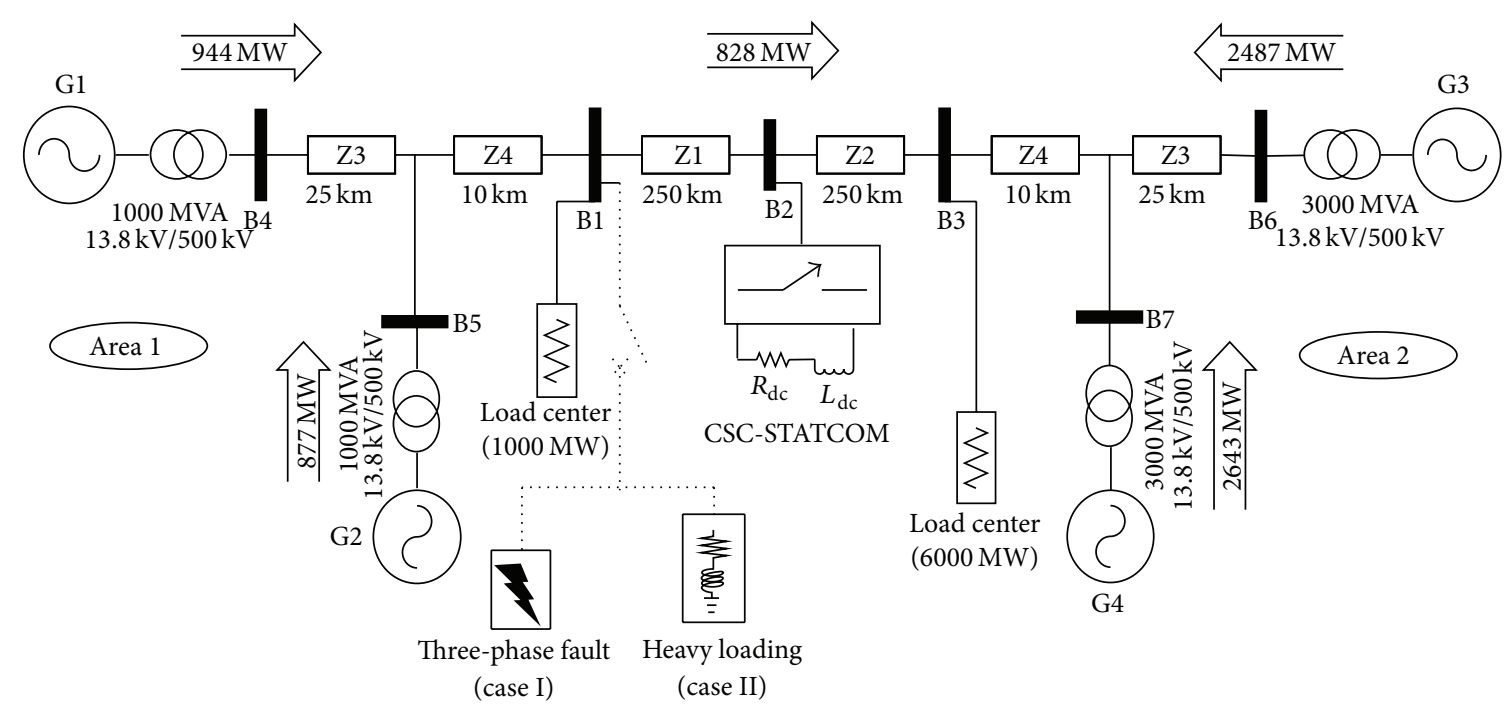

FIGURE 5: The single line diagram of the test-system model for transient stability study of multimachine power system.

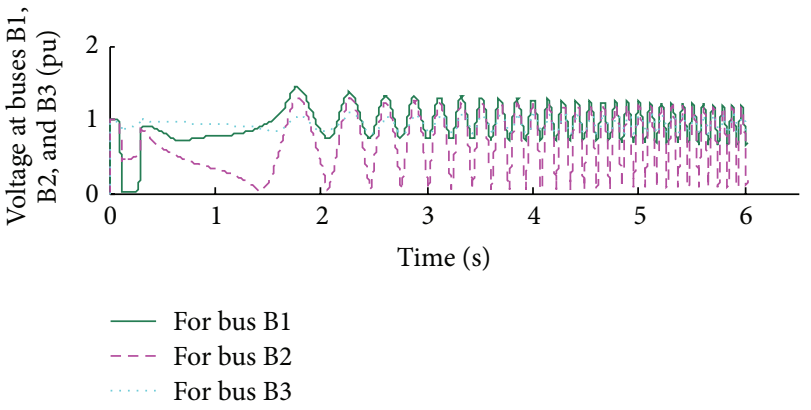

(a) Positive sequence voltages at different buses B1, B2, and B3

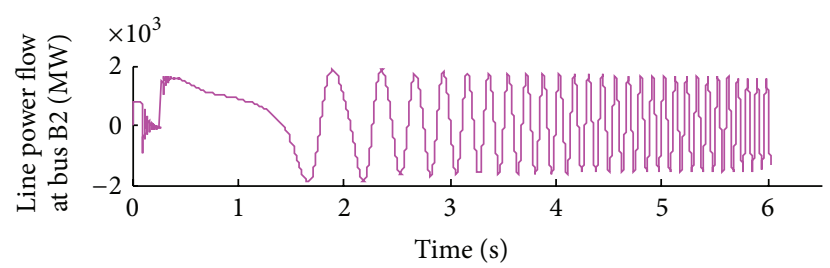

(b) Power flow at bus B2

FIGURE 6: System response without CSC-STATCOM for a threephase fault (case I).

is represented by $\omega_{1}, \omega_{2}, \omega_{3}$, and $\omega_{4}$, respectively. Here the critical clearing time (CCT) of fault is also found out for the test system stability by simulation. The fault time is increased in simulation to find the critical stability margin; thus CCT is obtained. CCT is defined as the maximal fault duration for which the system remains transiently stable [1]. CCT of the fault for the system with and without CSC-STATCOM is $325 \mathrm{~ms}$ and $276 \mathrm{~ms}$, respectively, as shown in Table 1. So it shows that CCT of fault is also increased due to the impact of pole-shifting controller based CSC-STATCOM. Clearly, waveforms show that proposed topology is more effective and robust performance than that of the without pole-shifting

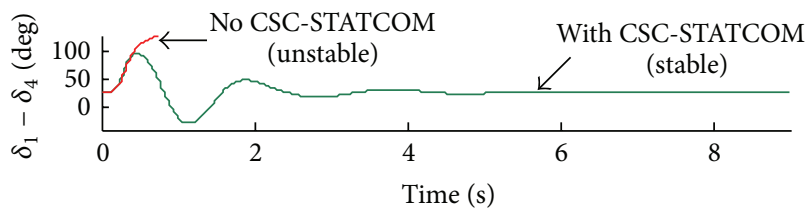

(a)

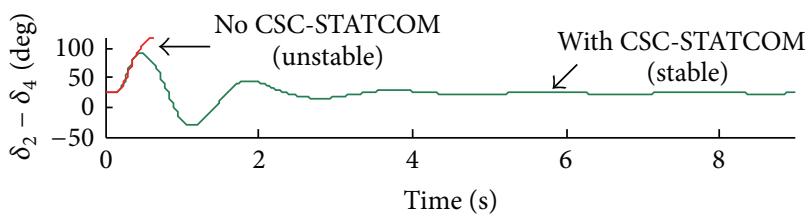

(b)

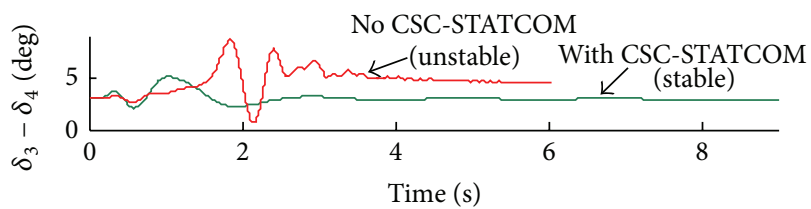

(c)

FIGURE 7: Variation of rotor angles differences of the test system for case I.

controller based CSC-STATCOM in terms of settling time, CCT, and transient stability of the test-system.

4.3. Case II-Large Loading. For heavy loading case, one large series load centre (200 MW/6000 Mvar) is connected at near bus B1 (i.e., at near machine G2) in Figure 5. This large loading is occurring only at time period $0.1 \mathrm{~s}$ to $0.466 \mathrm{~s}$. Due to this disturbance, the simulation results of test system with and without CSC-STATCOM are shown in Figures 11 to 15 . Clearly, the system is unstable in the absence of the pole-shifting controller based CSC-STATCOM device due to 


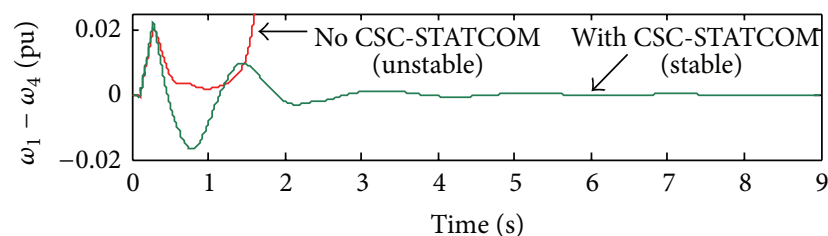

(a) Speed difference variation of machines G1 and G4

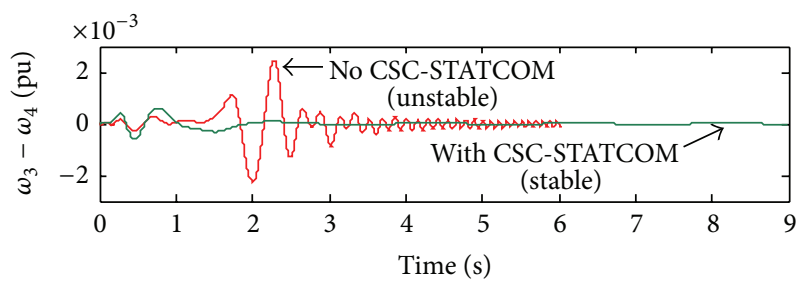

(b) Speed difference variation of machines G3 and G4

FIGURE 8: Speed differences variation of the test system for case I.

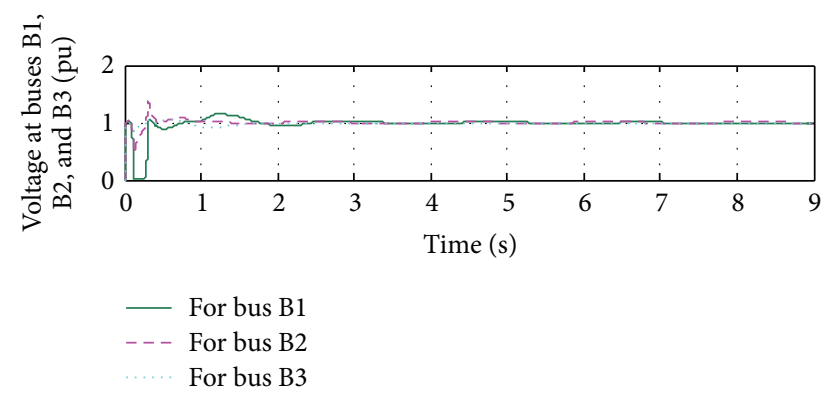

(a) Positive sequence voltages at different buses B1, B2, and B3

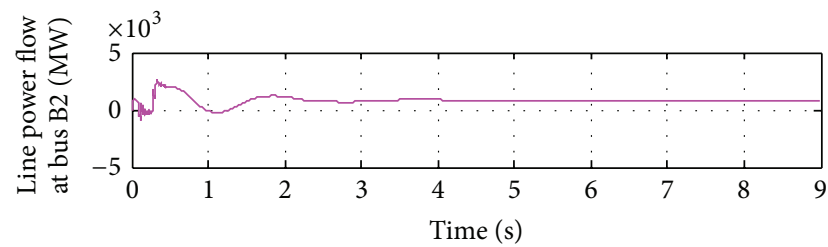

(b) Power flow at bus B2

FIGURE 9: Test system response with pole-shifting controller based CSC-STATCOM for a three-phase fault (case I).

TABLE 1: CCT of disturbances for the system stability with different topologies.

\begin{tabular}{lcc}
\hline $\begin{array}{l}\text { Case } \\
\text { number }\end{array}$ & System with different topologies & $\begin{array}{c}\text { Critical clearing } \\
\text { time (CCT) }\end{array}$ \\
\hline 1 & Without CSC-STATCOM & $276 \mathrm{~ms}$ \\
& With CSC-STATCOM & $325 \mathrm{~ms}$ \\
\hline 2 & Without CSC-STATCOM & $465 \mathrm{~ms}$ \\
& With CSC-STATCOM & $764 \mathrm{~ms}$ \\
\hline
\end{tabular}

this disturbance in Figures 11 to 13 and 15. But system with pole-shifting controller based CSC-STATCOM is continuing stable condition in Figures 12 to 15 . In Figure $12, \delta_{1}, \delta_{2}, \delta_{3}$,

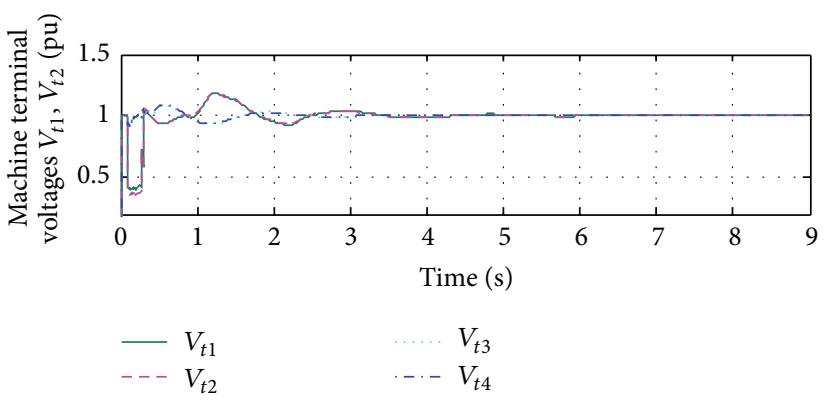

(a)

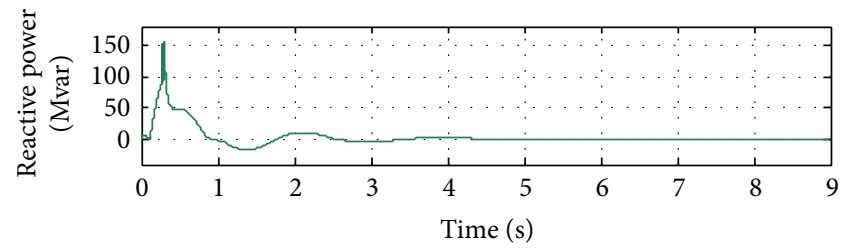

(b)

Figure 10: For case 1 (a) terminal voltages $V_{t 1}, V_{t 2}, V_{t 3}$, and $V_{t 4}$ of machine generators G1, G2, G3, and G4 with CSC-STATCOM, respectively, (b) reactive power inject (or absorb) by pole-shifting controller based CSC-STATCOM.

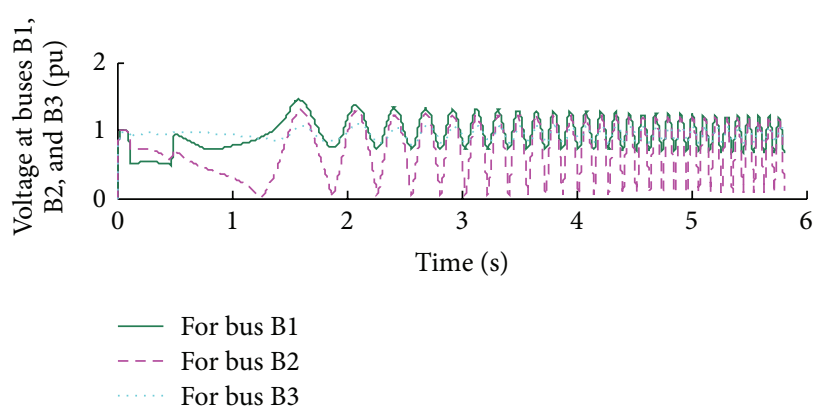

(a) Positive sequence voltages at different buses B1, B2, and B3

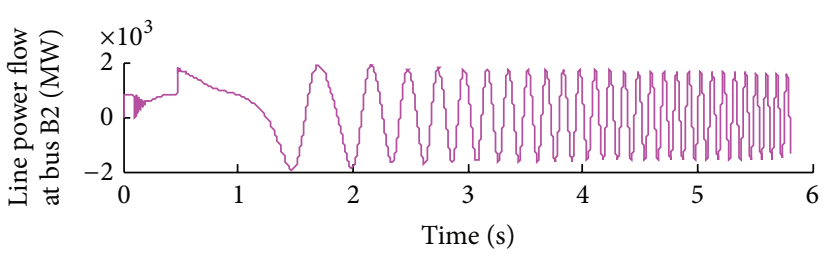

(b) Power flow at bus B2

FIgURE 11: Test-system response without CSC-STATCOM with a heavy loading (case II).

and $\delta_{4}$ are the rotor angles of machines G1, G2, G3, and G4, respectively. Figure 12 represents the variation of rotor angles differences of the multimachine system. In Figure 13, speeds of machines G1, G2, G3, and G4 are represented by $\omega_{1}, \omega_{2}, \omega_{3}$, and $\omega_{4}$, respectively. System voltages at different buses $\mathrm{B} 1, \mathrm{~B} 2$, and $\mathrm{B} 3$ with proposed scheme are shown in Figure 14. Here CCT for the system with and without CSCSTATCOM is $764 \mathrm{~ms}$ and $465 \mathrm{~ms}$, respectively, which are 
TABLE 2: CCT of disturbances for the test system stability with different shunt FACTS devices.

\begin{tabular}{lccc}
\hline S. number & Type of disturbances & FACTS devices & Critical clearing time (CCT) \\
\hline & & With SVC & $285 \mathrm{~ms}$ \\
1 & Fault condition & With VSC-STATCOM & $288 \mathrm{~ms}$ \\
& & With CSC-STATCOM & $325 \mathrm{~ms}$ \\
\hline & & With SVC & $486 \mathrm{~ms}$ \\
& Heavy loading condition & With VSC-STATCOM & $489 \mathrm{~ms}$ \\
& & With CSC-STATCOM & $764 \mathrm{~ms}$ \\
\hline
\end{tabular}

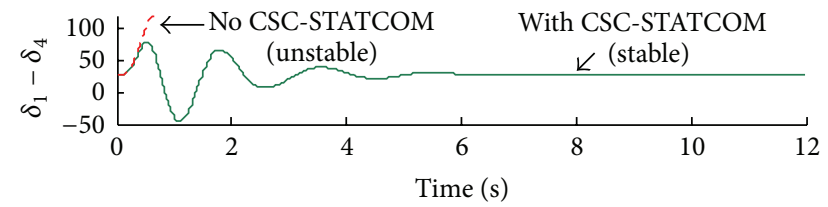

(a)

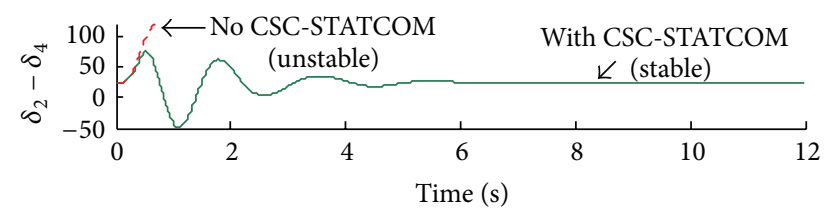

(b)

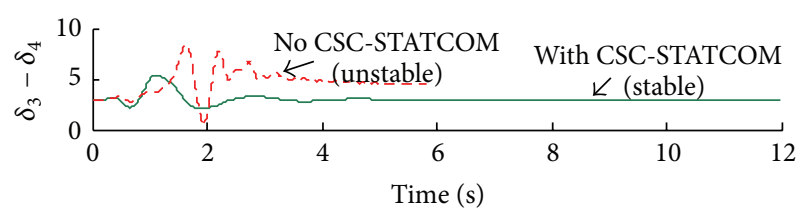

(c)

FIGURE 12: Variation of rotor angles differences of the test system in case II.

provided in Table 1. Clearly shown, CCT for test system is better due to the impact of pole-shifting controller based CSC-STATCOM. Hence the performance of the proposed scheme is still satisfactory in this case.

4.4. Case III-A Comparative Study. In order to show the robustness performance of the proposed scheme for improving the transient stability of the system, after this obtained outcomes from the proposed pole-shifting controller based CSC-STATCOM are compared to the obtained outcomes from the other shunt FACTS devices (SVC and VSC based STATCOM) which have been used in some most cited papers $[23,24]$. In this case, it has been assumed that the test system is same for all shunt FACTS devices and all shunt FACTS devices have the same rating (200 Mvar). After this, we check the impact of these shunt FACTS devices on the test system with three-phase fault condition. The obtained simulation results with these shunt FACTS devices are compared in Figure 16. In this figure system with SVC is reached in unstable condition. Here three-phase fault duration is $0.1 \mathrm{~s}$ to $0.285 \mathrm{~s}$. CCT for the system with different shunt FACTS devices is shown in Table 2. If heavy loading condition is applied during $0.1 \mathrm{~s}$ to $0.486 \mathrm{~s}$ in this case, then effect of this disturbance is shown in Figure 17. In all figures of Figures 16 and 17, multimachine power system with proposed topology based CSC-STATCOM is continuing stable condition. In these figures, the oscillations are damped more quickly and settled down after 3 to $4 \mathrm{sec}$ by proposed topology based CSC-STATCOM in comparison to other devices. In this comparative study, transient stability margin is also increased by increasing the CCT with the help of CSC-STATCOM device from Table 2. Clearly, waveforms show that CSC-STATCOM is more effective and robust performance than that of other shunt FACTS devices (SVC and VSC-STATCOM) in terms of oscillation damping, settling time, CCT, and transient stability of the multimachine power system in Figures 16 and 17.

\section{Conclusions}

In this paper, the dynamic modeling of CSC based STAT$\mathrm{COM}$ is studied and proposed pole-shifting controller for the best input-output response of CSC-STATCOM is presented in order to enhance the system transient stability of the multimachine power system with the different disturbances. The novelty in proposed approach lies in the fact that transient stability of a two-area four-machine power system is improved and critical clearing time of the disturbance is also increased. In this work, the proposed scheme is verified from MATLAB package. It has been also observed that pole-shifting controller based CSC-STATCOM can be more reliable and very effective rather than other shunt FACTS devices (SVC and VSC-STATCOM) in terms of oscillation damping, CCT, and transient stability of a multimachine power system. So, finally it can be said that CSC based STATCOM can be regarded as an alternative FACTS device to that of other shunt FACTS devices.

\section{Appendix}

Parameters for various components used in the test system configuration of Figure 5 are considered (all parameters are in pu unless specified otherwise) (see Table 3).

For All Generators of Multimachine Power System. Consider $V_{G}=13.8 \mathrm{kV} ; R_{s}=0.003 ; f=50 \mathrm{~Hz} ; X_{d}=1.305 ; X_{d}^{\prime}=$ $0.296 ; X_{d}^{\prime \prime}=0.252 ; X_{q}^{\prime}=0.50 ; X_{q}^{\prime \prime}=0.243 ; T_{d}^{\prime}=1.01 \mathrm{~s}$; $T_{d}^{\prime \prime}=0.053 \mathrm{~s} ; H=3.7 \mathrm{~s}$. 


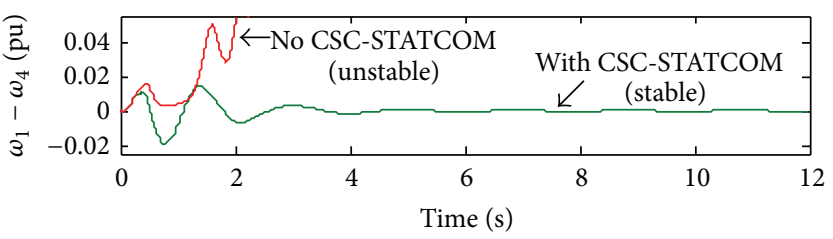

(a) Speed difference variation of machines G1 and G4

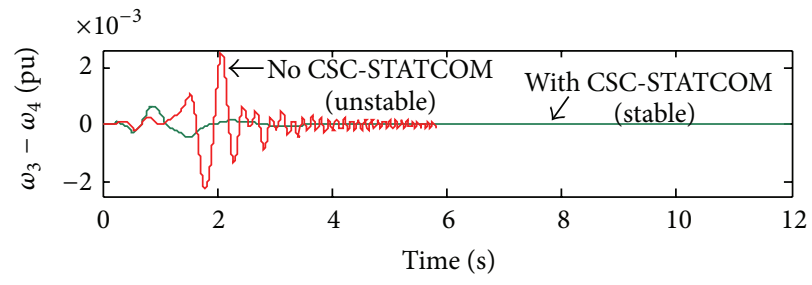

(b) Speed difference variation of machines G3 and G4

FIGURE 13: Speed differences variation of the multimachine system in case II.

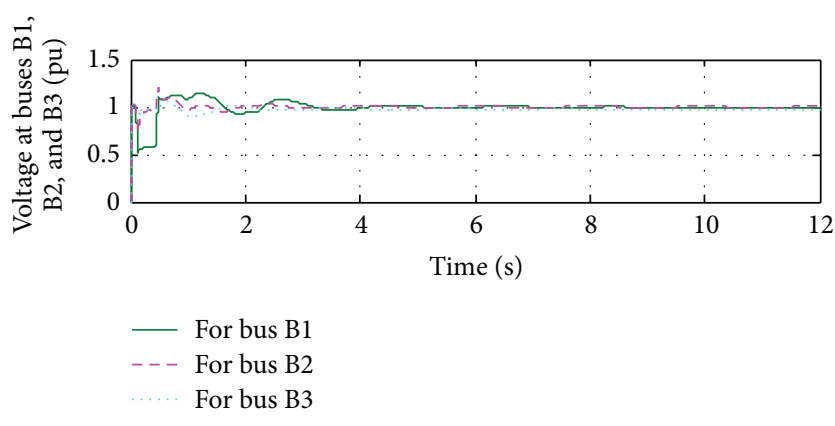

(a) Positive sequence voltages at different buses B1, B2, and B3

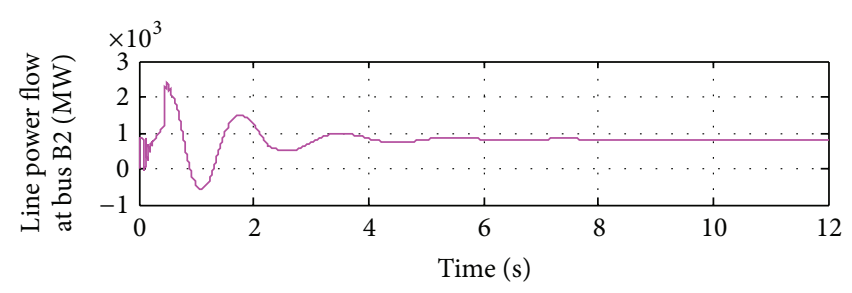

(b) Power flow at bus B2

FIGURE 14: Test system response with pole-shifting controller based CSC-STATCOM for a heavy loading (case II).

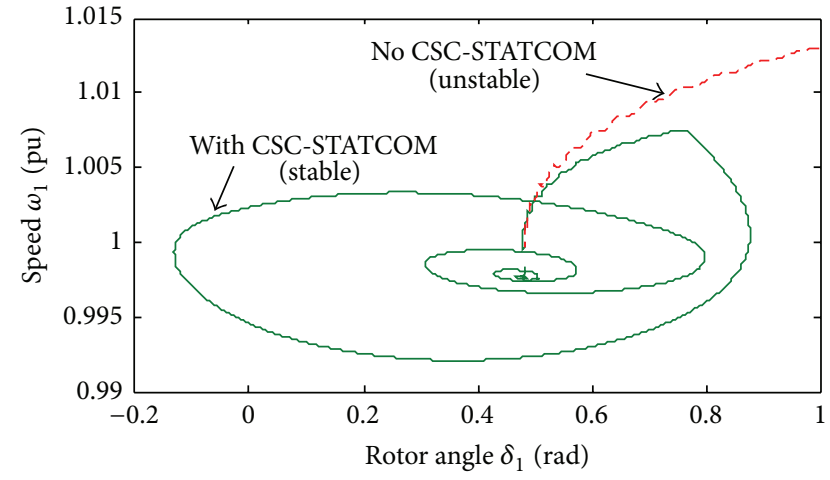

(a)

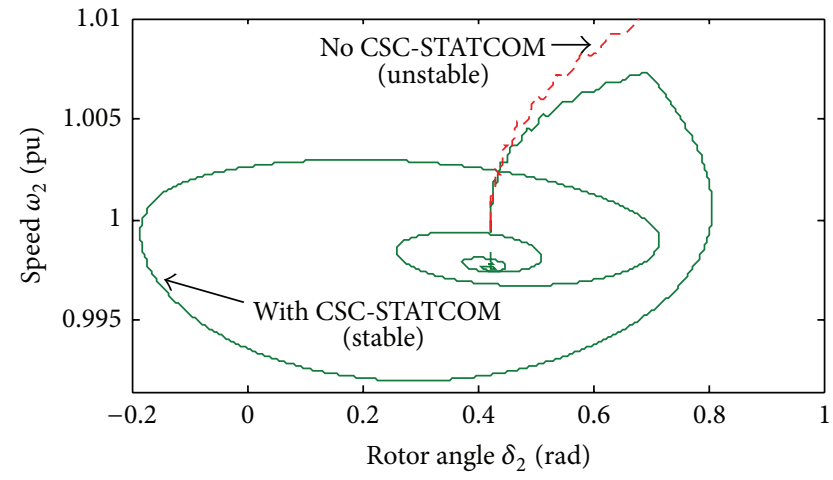

(b)

FIGURE 15: Speed versus rotor angle graph for (a) machine G1, (b) machine G2.

TABLE 3: Rating of multimachine system.

\begin{tabular}{lcccc}
\hline Machine & Input mechanical power $(\mathrm{pu})$ & Output electrical power $(\mathrm{MW})$ & Power rating (MVA) & Bus type \\
\hline G1 & 0.95 & 950 & 1000 & PV generation bus \\
G2 & 0.88 & 880 & 1000 & Swing bus \\
G3 & 0.83 & 2490 & 3000 & PV generation bus \\
G4 & 0.883 & 2649 & 3000 & Swing bus \\
\hline
\end{tabular}




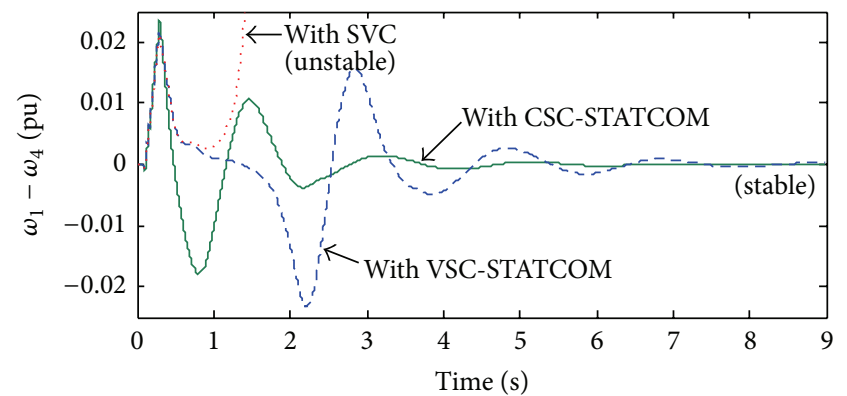

(a) Speed difference variation of machines G1 and G4

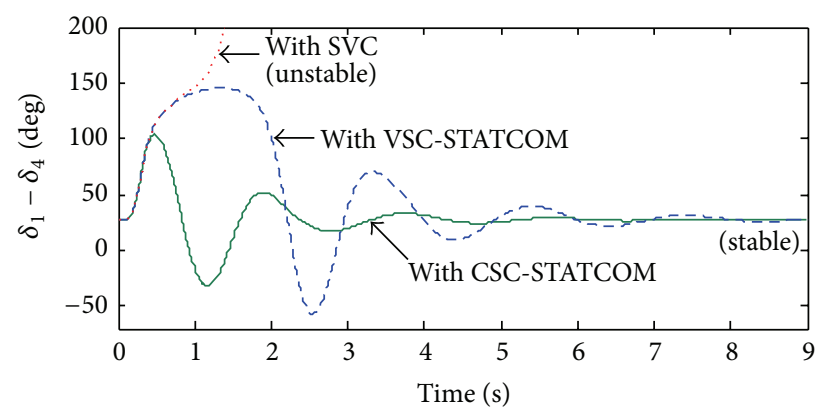

(c) Variation of rotor angles difference of machines G1 and G4

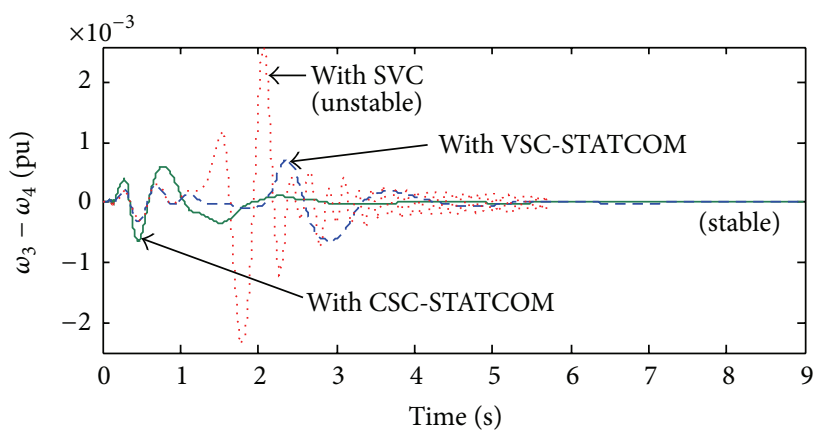

(b) Speed difference variation of machines G3 and G4

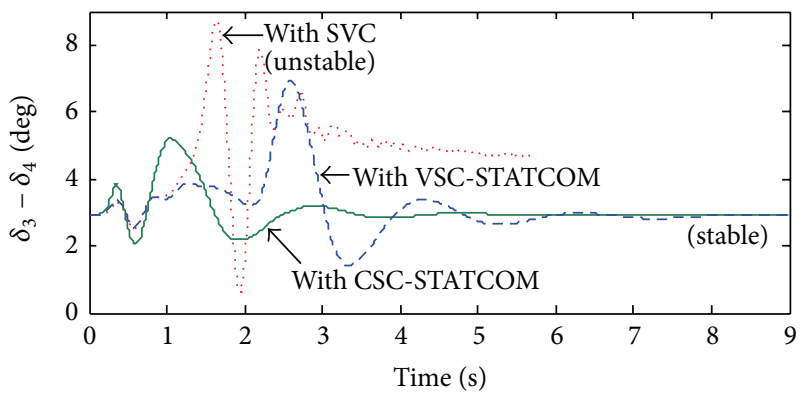

(d) Variation of rotor angles difference of machines G3 and G4

FIGURE 16: System response with different shunt FACTS devices (SVC, CSC-STATCOM, and VSC-STATCOM) for fault condition (case III).

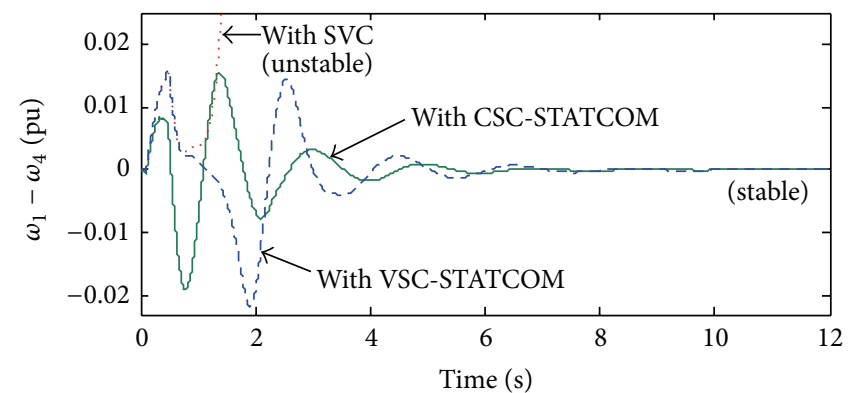

(a) Speed difference variation of machines G1 and G4

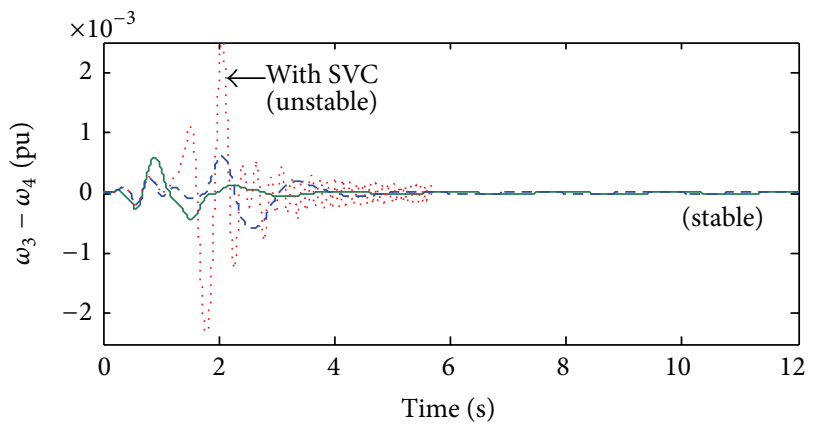

(..... SVC

- - VSC-STATCOM

— CSC-STATCOM

(b) Speed difference variation of machines G3 and G4

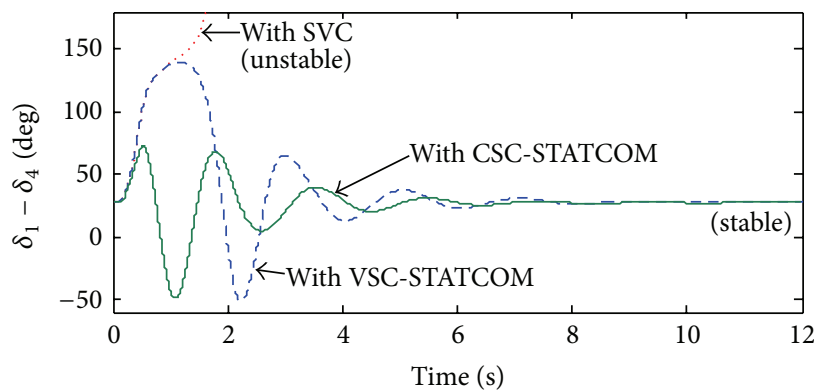

(c) Variation of rotor angles difference of machines G1 and G4

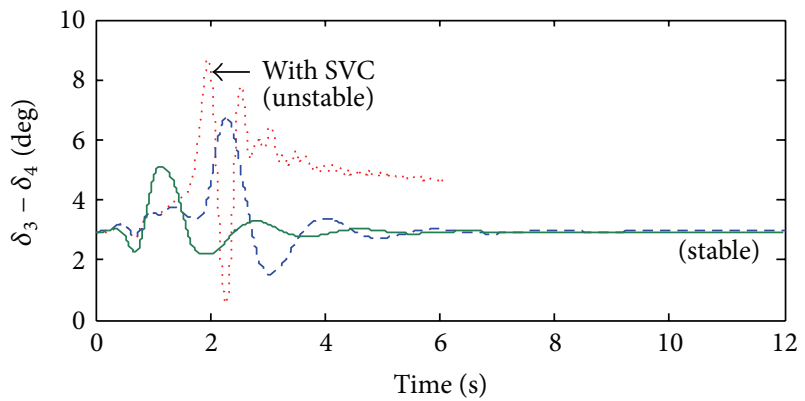

... SVC

- - - VSC-STATCOM

- CSC-STATCOM

(d) Variation of rotor angles difference of machines G3 and G4

FIGURE 17: System response with different shunt FACTS devices (SVC, CSC-STATCOM, and VSC-STATCOM) in a heavy loading condition (case III). 
( $R_{s}$ is stator winding resistance of generators; $V_{G}$ is generator voltage $(L-L) ; f$ is frequency; $X_{d}$ is synchronous reactance of generators; $X_{d}^{\prime}$ and $X_{d}^{\prime \prime}$ are the transient and subtransient reactance of generators in the direct-axis; $X_{q}^{\prime}$ and $X_{q}^{\prime \prime}$ are the transient and subtransient reactance of generators in the quadrature-axis; $T_{d}^{\prime}$ and $T_{d}^{\prime \prime}$ are the transient and subtransient open-circuit time constant; $H$ the inertia constant of machine.)

For Excitation Systems of Machines (G1, G2, G3, and G4). Regulator gain and time constant $\left(K_{a}\right.$ and $\left.T_{a}\right)$ are 200, $0.001 \mathrm{~s}$; gain and time constant of exciter $\left(K_{e}\right.$ and $\left.T_{e}\right)$ are $1,0 \mathrm{~s}$; damping filter gain and time constant $\left(K_{f}\right.$ and $\left.T_{f}\right)$ are 0.001 , $0.1 \mathrm{~s}$; upper and lower limit of the regulator output are 0,7 .

\section{Parameters of Shunt FACTS Devices}

$S V C$ : system nominal voltage $(L-L): 500 \mathrm{kV} ; f: 50 \mathrm{~Hz}$; $K_{p}=3 ; K_{i}=500 ; V_{\text {ref }}=1$.

VSC-STATCOM: system nominal voltage $(L-L)$ : $500 \mathrm{kV}$; DC link nominal voltage: $40 \mathrm{kV}$; DC link capacitance: $0.0375 \mu \mathrm{F} ; f: 50 \mathrm{~Hz} ; K_{p}=50 ; K_{i}=1000$; $V_{\text {ref }}=1$.

Pole-shifting controller based CSC-STATCOM: system nominal voltage $(L-L): 500 \mathrm{kV} ; R_{\mathrm{dc}}=0.01 \Omega ; L_{\mathrm{dc}}=$ $40 \mathrm{mH} ; C=400 \mu \mathrm{F} ; R=0.3 \Omega ; L=2 \mathrm{mH} ; \omega=314$; $E_{d(\mathrm{ref})}=1$, PI parameters $\left(K_{p}=70 ; K_{i}=1800\right)$.

\section{Conflict of Interests}

The authors declare that there is no conflict of interests regarding the publication of this paper.

\section{References}

[1] P. Kundur, Power System Stability and Control, McGraw-Hill, New York, NY, USA, 1994.

[2] M. A. Abido, "Power system stability enhancement using facts controllers: a review," The Arabian Journal for Science and Engineering, vol. 34, no. 2, pp. 153-172, 2009.

[3] C.-X. Dou, S.-L. Guo, and X.-Z. Zhang, "Improvement of transient stability for power systems using wide-area measurement signals," Electrical Engineering, vol. 91, no. 3, pp. 133-143, 2009.

[4] X. D. Liu, Y. Li, Z. J. Liu et al., "A novel fast transient stability prediction method based on pmu," in Proceedings of the IEEE Power \& Energy Society General Meeting ( PES '09), pp. 1-5, IEEE, Calgary, Canada, July 2009.

[5] R. J. Nelson, J. Bian, D. G. Ramey, T. A. Lemak, T. R. Rietman, and J. E. Hill, "Transient stability enhancement with FACTS controllers," in Proceedings of the 6th International Conference on AC and DC Power Transmission, pp. 269-274, May 1996.

[6] S. H. Hosseini and A. Ajami, "Transient stability enhancement of AC transmission system using STATCOM," in Proceedings of the IEEE Region 10 Conference on Computers, Communications, Control and Power Engineering (TENCON '02), vol. 3, pp. 18091812, October 2002.

[7] M. H. Haque, "Improvement of first swing stability limit by utilizing full benefit of shunt facts devices," IEEE Transactions on Power Systems, vol. 19, no. 4, pp. 1894-1902, 2004.
[8] Y. L. Tan and Y. Wang, "A robust nonlinear excitation and SMES controller for transient stabilization," International Journal of Electrical Power and Energy System, vol. 26, no. 5, pp. 325-332, 2004.

[9] A. Chakraborty, S. K. Musunuri, A. K. Srivastava, and A. K. Kondabathini, "Integrating STATCOM and battery energy storage system for power system transient stability: a review and application," Advances in Power Electronics, vol. 2012, Article ID 676010, 12 pages, 2012.

[10] N. C. Sahoo, B. K. Panigrahi, P. K. Dash, and G. Panda, "Multivariable nonlinear control of STATCOM for synchronous generator stabilization," International Journal of Electrical Power and Energy System, vol. 26, no. 1, pp. 37-48, 2004.

[11] H. Tsai, C. Chu, and S. Lee, "Passivity-based nonlinear STATCOM controller design for improving transient stability of power systems," in Proceedings of the IEEE/PES Transmission and Distribution Conference \& Exhibition: Asia and Pacific, pp. 1-5, IEEE, Dalian, China, 2005.

[12] Y. L. Tan, "Analysis of line compensation by shunt-connected FACTS controllers: a comparison between SVC and STATCOM," IEEE Power Engineering Review, vol. 19, no. 8, pp. 57-58, 1999.

[13] N. G. Hingorani and L. Gyugyi, Understanding FACTS: Concepts and Technology of Flexible AC Transmission Systems, IEEE Press, New York, NY, USA, 1999.

[14] L. Gyugyi, "Application characteristics of converter-based FACTS controllers," in Proceedings of the International Conference on Power System Technology (PowerCon '00), vol. 1, pp. 391396, Piscataway, NJ, USA, December 2000.

[15] B. Han, S. Moon, J. Park, and G. Karady, "Static synchronous compensator using thyristor PWM current source inverter," IEEE Transactions on Power Delivery, vol. 15, no. 4, pp. 12851290, 2000.

[16] H. F. Bilgin and M. Ermis, "Current source converter based STATCOM: operating principles, design and field performance," Electric Power Systems Research, vol. 81, no. 2, pp. 478487, 2011.

[17] S. Gupta, R. K. Tripathi, and R. D. Shukla, "Voltage stability improvement in power systems using facts controllers: stateof-the-art review," in Proceedings of the IEEE International Conference on Power, Control and Embedded Systems (ICPCES 2010), pp. 1-8, Allahabad, India, December 2010.

[18] M. Kazerani and Y. Ye, "Comparative evaluation of threephase PWM voltage- and current-source converter topologies in FACTS applications," in Proceedings of the IEEE Power Engineering Society Summer Meeting, vol. 1, pp. 473-479, July 2002.

[19] D. Shen and P. W. Lehn, "Modeling, analysis, and control of a current source inverter-based STATCOM," IEEE Transactions on Power Delivery, vol. 17, no. 1, pp. 248-253, 2002.

[20] Y. Ni, L. Jiao, S. Chen, and B. Zhang, "Application of a nonlinear PID controller on STATCOM with a differential tracker," in Proceedings of the 2nd International Conference on Energy Management and Power Delivery (EMPD '98), pp. 29-34, New York, NY, USA, March 1998.

[21] S. Gupta and R. K. Tripathi, "An LQR and pole placement controller for CSC based STATCOM," in Proceedings of the International Conference on Power, Energy and Control (ICPEC '13), pp. 115-119, February 2013.

[22] P. Rao, M. L. Crow, and Z. Yang, "STATCOM control for power system voltage control applications," IEEE Transactions on Power Delivery, vol. 15, no. 4, pp. 1311-1317, 2000. 
[23] S. Panda and R. N. Patel, "Improving power system transient stability with an off-centre location of shunt FACTS devices," Journal of Electrical Engineering, vol. 57, no. 6, pp. 365-368, 2006.

[24] Z. Y. Zou, Q. Y. Jiang, Y. J. Cao, and H. F. Wang, "Normal form analysis of interactions among multiple SVC controllers in power systems," IEE Proceedings-Generation, Transmission and Distribution, vol. 152, no. 4, pp. 469-474, 2005.

[25] C. Schauder and H. Mehta, "Vector analysis and control of advanced static VAR compensators," IEE Proceedings C: Generation Transmission and Distribution, vol. 140, no. 4, pp. 299-306, 1993.

[26] S. Gupta and R. K. Tripathi, "Transient stability assessment of two-area power system with robust controller based CSCSTATCOM," Journal of Control Engineering and Applied Informatics, vol. 16, no. 3, pp. 3-12, 2014.

[27] B. T. Ooi, M. Kazerani, R. Marceau et al., "Mid-point sitting of facts devices in transmission lines," IEEE Transactions on Power Delivery, vol. 12, no. 4, pp. 1717-1722, 1997. 

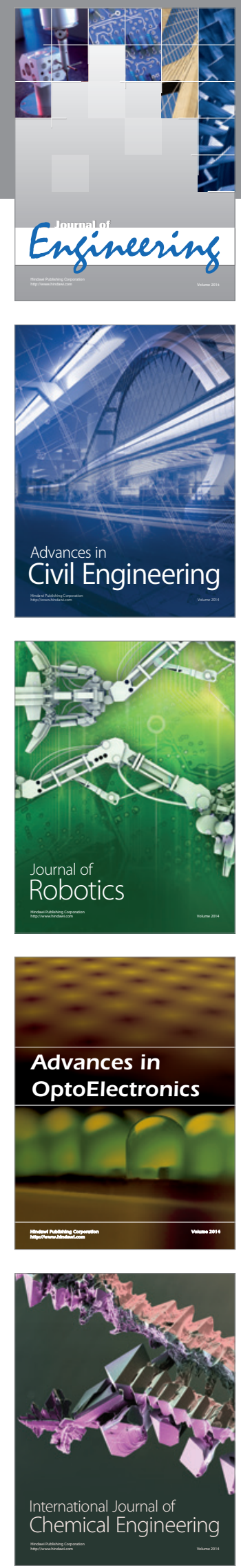

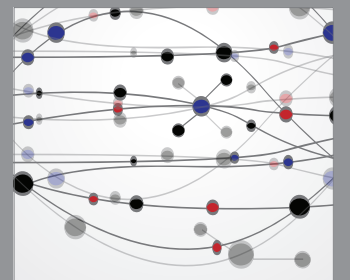

The Scientific World Journal
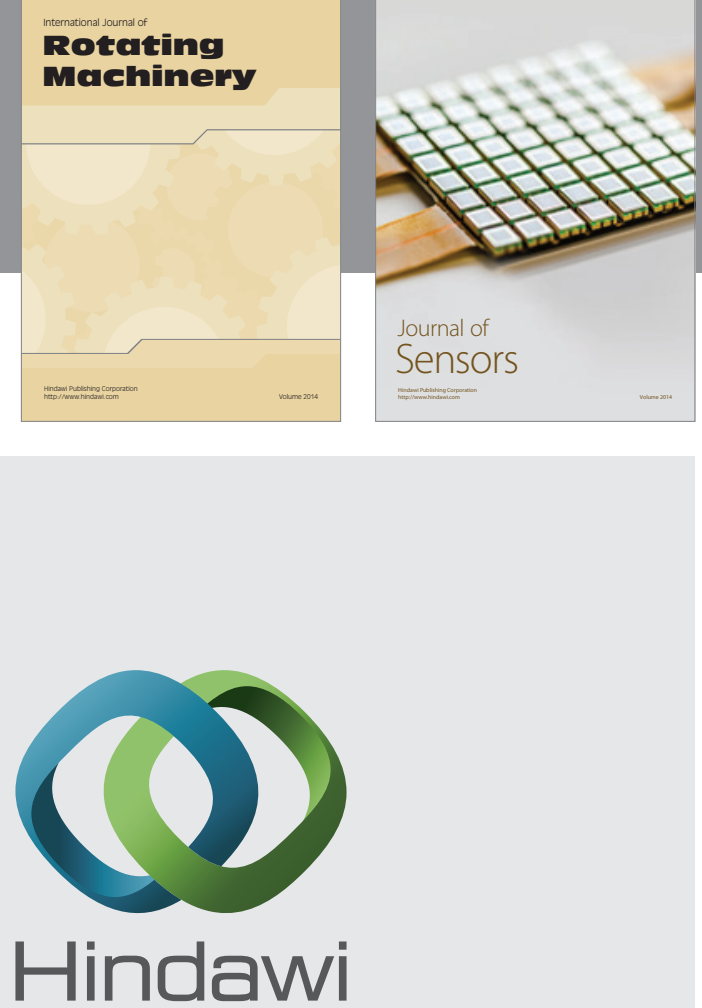

Submit your manuscripts at http://www.hindawi.com
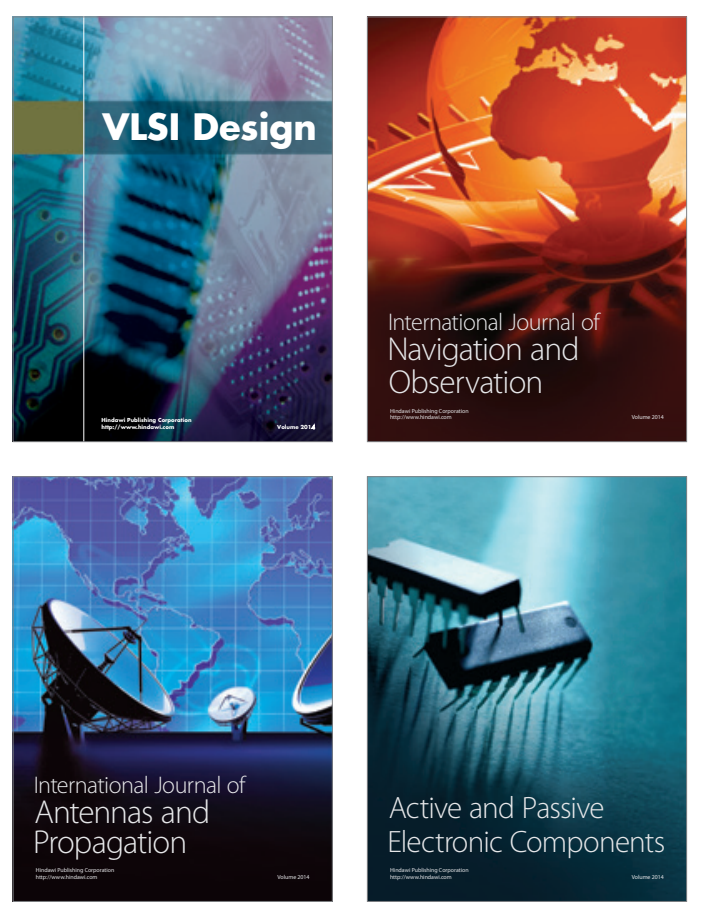
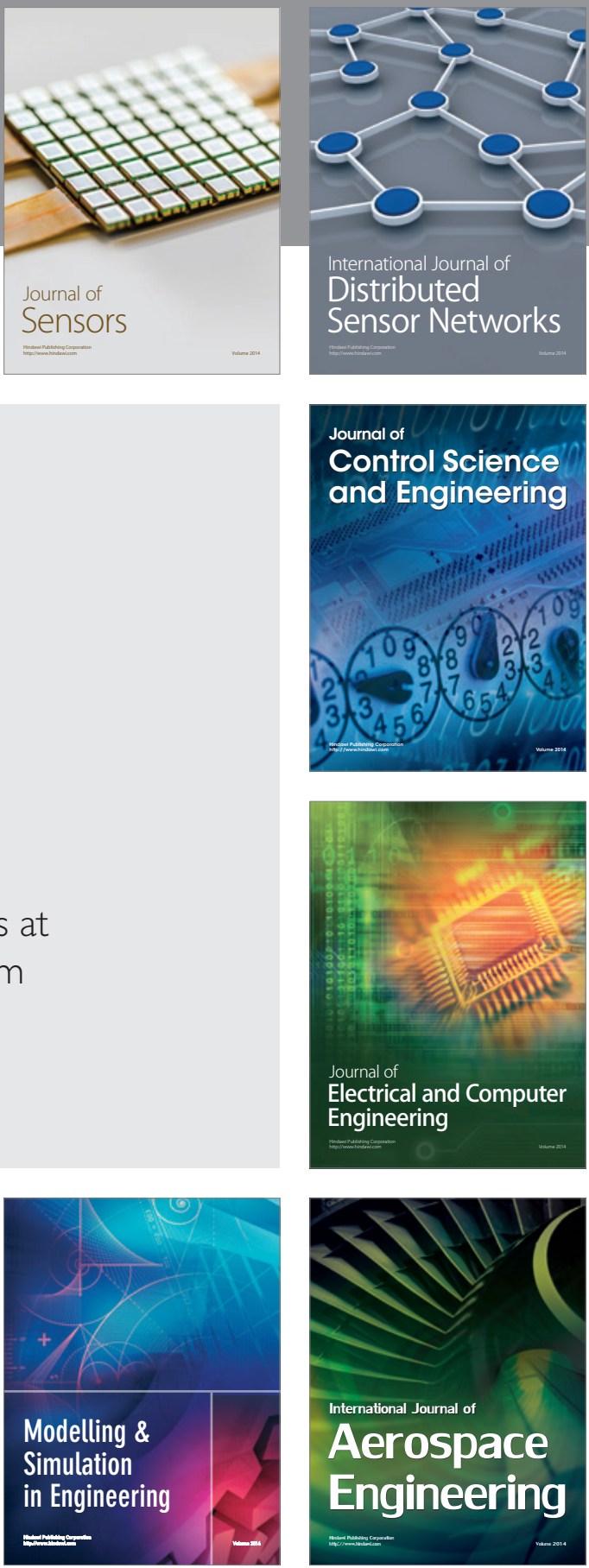

Journal of

Control Science

and Engineering
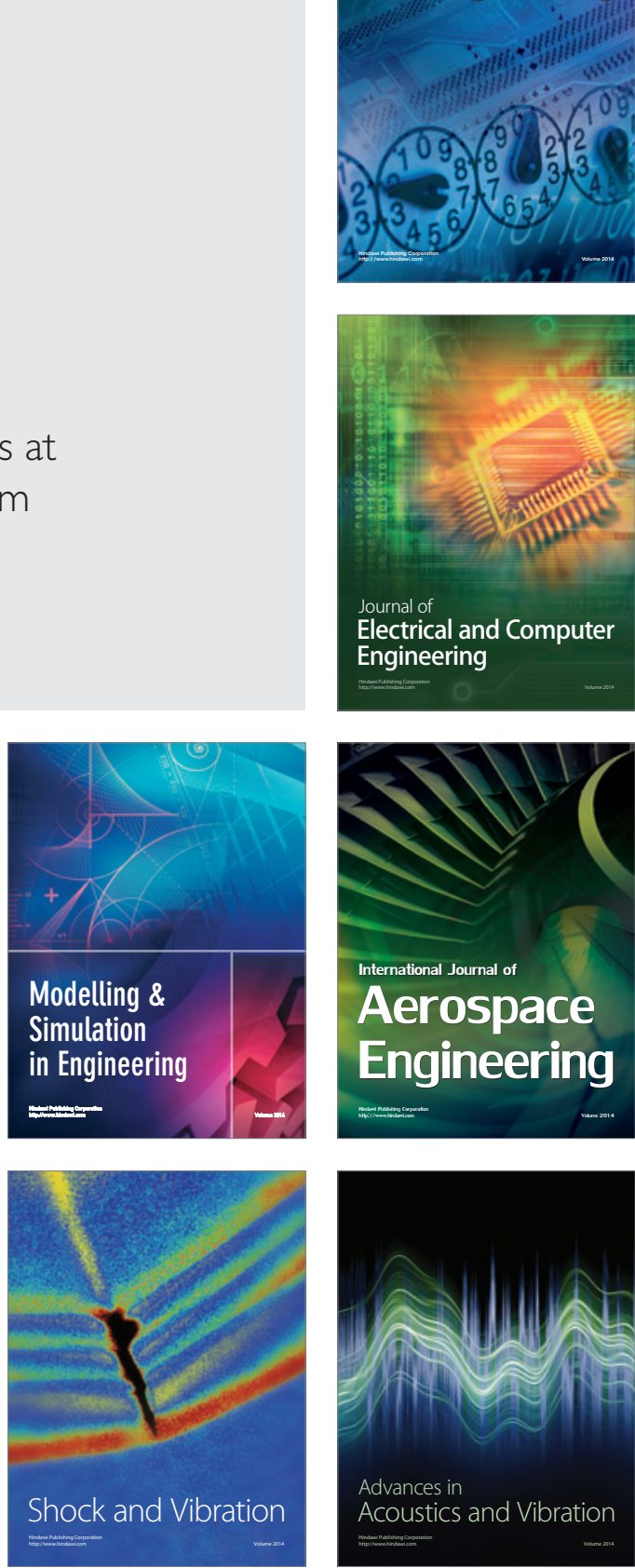